\title{
Dietary calcium intake and rate of bone loss in men
}

\author{
Sarah M. Bristow*, Gregory D. Gamble, Anne M. Horne and Ian R. Reid \\ Department of Medicine, University of Auckland, Private Bag 92019, Auckland Mail Centre 1142, New Zealand
}

(Submitted 30 November 2016 - Final revision received 7 May 2017 - Accepted 8 May 2017 - First published online 13 June 2017)

\section{Abstract}

A high Ca intake has been recommended for osteoporosis prevention; however, little research has examined the relationship between dietary $\mathrm{Ca}$ and bone health in men. We examined associations between dietary Ca intake, bone mineral density (BMD) and change in BMD at the total body, hip and spine over 2 years in a cohort of men (mean age 57 years, BMI $26 \mathrm{~kg} / \mathrm{m}^{2}$ ) from a trial. Data from the total cohort ( $n 323$ ) were used in the analysis of $\mathrm{Ca}$ intake and BMD at baseline, and data from the placebo group ( $n$ 99) were used in the longitudinal analysis of Ca intake and change in BMD. Parathyroid hormone (PTH) and the markers of bone turnover serum total alkaline phosphatase activity, serum C-telopeptide and serum procollagen type-1 N-terminal propeptide were measured in a subset of participants at baseline ( $n$ 150), and associations with dietary $\mathrm{Ca}$ at baseline were examined. Mean Ca intake was $870 \mathrm{mg} / \mathrm{d}$. Baseline BMD was not related to dietary Ca intake at any site, before or after adjustment for covariables. Similarly, bone loss over 2 years was not related to Ca intake at any site, before or after adjustment. Dietary Ca intake was inversely correlated with PTH at baseline $(r-0 \cdot 19, P=0 \cdot 02)$, but was not associated with the markers of bone turnover. BMD and rates of bone loss were unrelated to $\mathrm{Ca}$ intake in these men. This suggests that strategies to increase Ca intake are unlikely to impact on the prevalence of and morbidity from male osteoporosis.

Key words: Dietary calcium: Bone density: Osteoporosis: Prospective studies: Cross-sectional studies

Osteoporosis, with its clinical sequelae of fracture, is a wellrecognised health problem among women, but also represents a significant health burden among men. The remaining-lifetime risk for fracture for a man aged 50 years is approximately $22 \%{ }^{(1)}$, and one-third of hip fractures worldwide occur in men ${ }^{(2)}$. Men tend to lose bone slowly but continuously from the time peak bone mass is achieved in early adulthood ${ }^{(3-5)}$, with rates of loss increasing with advancing age ${ }^{(6)}$. As a result of the rapid ageing of the population and increased longevity among men, the health burden of osteoporotic fractures among men is increasing ${ }^{(1,7)}$. There is thus presently a need for evidence-based recommendations that reduce bone loss and fracture risk in men.

In clinical practice guidelines, increasing $\mathrm{Ca}$ intake to the recommended levels is one of the most widely recommended strategies for osteoporosis prevention ${ }^{(8)}$. However, most recommendations regarding the level of $\mathrm{Ca}$ intake required for bone health have been developed based on the findings of early Ca-balance studies ${ }^{(9)}$, a method with several deficiencies $^{(10,11)}$. Importantly, Ca balance has never been shown to be associated with fracture risk. The advent of bone densitometry has since allowed the accurate assessment of bone mineral density (BMD), which does predict fracture risk $^{(12)}$. Sequential measurements of bone density over time allow the direct measure of bone balance, obviating the need for the surrogate measure of $\mathrm{Ca}$ balance.
The small effects of Ca supplements on bone in clinical trials have also been considered evidence that higher dietary $\mathrm{Ca}$ intakes are necessary for bone health ${ }^{(9)}$. There are issues with using such trials to estimate the relationship between long-term dietary intake and bone. For example, Ca supplementation results in only a one-off gain in BMD of approximately $1 \%$, with no further effect on bone loss beyond 1 year of treatment ${ }^{(13)}$. Furthermore, most trials have examined doses of $1000 \mathrm{mg} / \mathrm{d}$ of supplemental $\mathrm{Ca}$ in addition to mean dietary $\mathrm{Ca}$ intakes of $700-800 \mathrm{mg} / \mathrm{d}$, and therefore cannot provide information about the effects of variation in $\mathrm{Ca}$ intake within the normal dietary range.

For these reasons, prospective cohort studies with sequential measurements of bone density provide the best tool for estimating the relationship between long-term dietary $\mathrm{Ca}$ intake and bone health. Although many studies have examined the relationship between dietary $\mathrm{Ca}$ intake and bone loss in women, only a few have done so in men ${ }^{(14-17)}$. We previously reported the results of a randomised controlled trial in men ${ }^{(18)}$, in which treatment with $1200 \mathrm{mg} / \mathrm{d}$ of supplemental $\mathrm{Ca}$ for 2 years increased BMD by $1-1.5 \%$ relative to the placebo, and $600 \mathrm{mg} / \mathrm{d}$ had no effect. However, for the reasons described above, the effects of short-term, high-dose $\mathrm{Ca}$ interventions on BMD are unlikely to represent those of long-term dietary intake. We have therefore used data from this trial of men to examine

Abbreviations: 25(OH)D, 25-hydroxyvitamin D; BMD, bone mineral density; PINP, procollagen type-1 N-terminal propeptide; PTH, parathyroid hormone.

* Corresponding author: S. M. Bristow, email s.bristow@auckland.ac.nz 
the relationship between dietary $\mathrm{Ca}$ intake and BMD at baseline, and in the placebo group, dietary $\mathrm{Ca}$ intake and change in BMD over time. Higher $\mathrm{Ca}$ intakes are thought to improve BMD by decreasing the parathyroid hormone (PTH) level and thereby bone turnover, hence we also examined the influence of $\mathrm{Ca}$ intake on these parameters.

\section{Methods \\ Participants}

The present cohort ( $n$ 323) is from a randomised, controlled trial in healthy men, designed to assess the effects of $\mathrm{Ca}$ supplementation on bone density over a period of 2 years. This study has previously been described in detail ${ }^{(18)}$. We recruited participants through newspaper advertisement. Participants were aged over 40 years and not receiving therapy for osteoporosis or taking Ca supplements. At recruitment, they were free of major illness (including untreated hypo- or hyperthyroidism, liver disease, malignancy or metabolic bone disease), had serum creatinine $<0.2 \mathrm{mmol} / \mathrm{l}$ and serum 25-hydroxyvitamin $\mathrm{D}>25 \mathrm{nmol} / \mathrm{l}$. Lumbar spine and total hip BMD $z$-scores were $>-2$ (USA (Combined National Health and Nutrition Examination Survey (NHANES)/Lunar), Femur Reference Population (v112) and AP Spine Reference Population (v112)). None of the participants had been regular users of testosterone, anabolic steroids, glucocorticoids or bisphosphonates in the previous 1 year. None of the participants were taking vitamin D supplements. The study started in 2004 and was completed in 2007. A total of 107 men were randomised to the placebo arm of this trial, of whom 104 completed the study. Three participants from this group received a bone-active medication ( $\mathrm{Ca}$, prednisone or bisphosphonates) at some time during the study, and thus were excluded from the longitudinal analyses presented here. Two participants did not complete the baseline dietary $\mathrm{Ca}$ assessment and were also excluded, resulting in $n 99$ for the longitudinal analyses.

\section{Measurements}

BMD was measured at baseline and at 24-months at the lumbar spine (L1-4), at both total hips and at the total body using a Prodigy dual-energy X-ray absorptiometer (GE Lunar). The $\mathrm{CV}$ for measurement of total hip and lumbar spine BMD in our laboratory are 1.1 and $1.4 \%$, respectively. The serum 25-hydroxyvitamin D (25(OH)D) level was measured by RIA (DiaSorin) in the first 212 men, and by a chemiluminescent assay (Nichols) in the last 111 men. The interassay CV for the DiaSorin assay was $8.8 \%$ and for the Nichols assay was $7.5 \%$ in our laboratory. Our laboratory meets the performance targets for the Vitamin D External Quality Assessment Scheme ${ }^{(19)}$ for both assays. Results obtained using the Nichols assay were converted to DiaSorin results as we have described previously $^{(20)}$. Total alkaline phosphatase (ALP) activity was assessed using the Roche assay on the Roche Modular autoanalyser (Roche Diagnostics), which is an International Federation of Clinical Chemistry standardised method. The CV of the assay was $2 \%$. Serum C-telopeptide (CTX) and serum procollagen type-1 N-terminal propeptide (PINP) were measured using an electrochemiluminescence method on the Roche Elecsys 2010 platform (Roche Diagnostics). The CV were 5.1 and $1.9 \%$, respectively. Intact PTH was measured using an electrochemiluminescence immunoassay on the Roche E170 Modular analyser (Roche Diagnostics). The interassay CV for PTH was $6 \cdot 1 \%$. These assays were performed in 150 participants (fifty from the placebo group and fifty from each of the two active treatment groups).

Dietary $\mathrm{Ca}$ intake was assessed at baseline and at 2 years using an abbreviated FFQ previously validated for use with Caucasian women ${ }^{(21)}$. We have previously shown Ca intake assessed with this instrument to be inversely related to circulating PTH levels in normal postmenopausal women ${ }^{(22)}$. Dietary vitamin D intake was determined using a 24-h food diary analysed with FoodWorks software. Body weight was measured using electronic scales, and height was measured using a Harpenden stadiometer (Holtain). Fracture history, smoking status and physical activity level were assessed by a questionnaire, with the metabolic equivalent of task calculated as described previously ${ }^{(23)}$. This study was conducted according to the guidelines laid down in the Declaration of Helsinki and all procedures involving human subjects were approved by the local ethics committee. Written informed consent was obtained from all participants. The study was registered with the Australian Clinical Trials Registry, ACTRN 012605000274673.

\section{Statistics}

Analyses were completed using SAS (SAS version 9.4; SAS Institute Inc.). In a cross-sectional analysis involving all available baseline data, univariate correlation (Pearson's normally distributed variables) and ordinary least squares linear regression as well as multiple linear regression were performed with BMD, PTH and bone turnover markers as the dependent variables, and dietary $\mathrm{Ca}$, age, weight, height, serum $25(\mathrm{OH}) \mathrm{D}$, physical activity and smoking status as the independent variables. Variables were chosen for the multivariable analysis on the basis that they were considered likely to be related to the dependent variables and to avoid over-fitting; reduced models were then run including any variable in the fully saturated model with $P<0 \cdot 15$. Collinearity diagnostics and goodness-of-fit statistics were examined for model stability. Differences in the means of each dependent variable between tertiles of baseline dietary Ca were tested using ANOVA (general linear modelling) with and without potentially confounding covariates (age, weight, height, serum 25(OH)D, physical activity and smoking status).

A similar analysis was carried out on the change from baseline to 2 years (longitudinal subset, $n$ 99) for each of the dependent variables in the subset of participants randomised to placebo, and who did not commence bone-active medications during follow-up.

All tests were two-tailed. $P<0.05$ was considered statistically significant and no adjustment for multiplicity was made.

\section{Justification of sample size}

This study efficiently uses all data from a randomised placebo controlled trial of $\mathrm{Ca}$ supplementation and $\mathrm{BMD}^{(18)}$. In testing 
for associations between variables cross-sectionally at baseline in the entire study cohort ( $n$ 323), there is adequate power ( $80 \%$ ) at the $5 \%$ significance level to detect correlations of at least $0 \cdot 16$. In the longitudinal analysis ( $n$ 99), correlations of at least 0.28 could be detected. These correlations represent small to medium effect sizes and are likely to be of scientific interest. Estimation of minimum detectable effect size for a correlation was made using PASS 2002.

\section{Results}

The baseline characteristics of the men are presented in Table 1. The mean Ca intake was 870 (range 110-2630) mg/d. The mean age of men was 57 (range 39-88) years. The cohort was unremarkable with respect to clinical and biochemical variables.

\section{Cross-sectional analysis}

First, we examined correlations between dietary Ca intake, BMD, PTH and the markers of bone turnover at baseline ( $n 323$ for BMD and $n 150$ for PTH and the markers of bone turnover). Baseline dietary $\mathrm{Ca}$ intake was not correlated with baseline BMD at the total body, the total hip or at the lumbar spine (Fig. 1). To determine whether associations with dietary $\mathrm{Ca}$ intake were present once potential confounders had been adjusted for, we performed multiple regression analyses with
BMD at each site as the dependent variable and dietary $\mathrm{Ca}$, age, weight, height, serum $25(\mathrm{OH}) \mathrm{D}$, physical activity and smoking status as the independent variables. Dietary Ca did not reach the required level of significance $(P>0 \cdot 15)$ for inclusion in the models for BMD at any site. To test for non-linear associations, we examined the mean BMD by tertile of dietary Ca intake $(<660,660-920$ and $>920 \mathrm{mg} / \mathrm{d})$. No differences in BMD were found across the tertiles at the total body $(P=0.39)$, total hip $(P=0.57)$ or at the spine $(P=0.35)$; this did not change after adjusting for weight, height, age, serum $25(\mathrm{OH}) \mathrm{D}$, physical activity and smoking.

PTH and the markers of bone turnover ALP, CTX and PINP were measured in a subset of 150 participants at baseline (fifty from the placebo group of the original trial and fifty from each of the two Ca-supplemented groups). Dietary $\mathrm{Ca}$ intake was inversely correlated with PTH at baseline (Fig. $2 ; r-0 \cdot 19$, $P=0.02)$. In multiple regression analyses, dietary $\mathrm{Ca}$ remained a significant predictor of PTH $(P=0.03)$ in a model that also included age, height, weight and serum 25(OH)D (Table 2). Dietary Ca intake was not correlated with ALP $(r-0 \cdot 09, P=0 \cdot 26)$, CTX $(r-0 \cdot 10, P=0 \cdot 25)$ or PINP $(r 0.003, P=0 \cdot 96)$ and was not a significant predictor of these markers in multiple regression analyses. When we compared these parameters across tertiles of dietary $\mathrm{Ca}$ intake, no significant differences were found for PTH $(P=0 \cdot 20)$, ALP $(P=0 \cdot 48)$, CTX $(P=0 \cdot 58)$ or PINP $(P=0 \cdot 33)$, and this did not change after adjusting for covariables.

Table 1. Baseline characteristics of participants

(Mean values and standard deviations; numbers and percentages)

\begin{tabular}{|c|c|c|c|c|}
\hline & \multicolumn{2}{|c|}{ Cross-sectional analysis ( $n$ 323) } & \multicolumn{2}{|c|}{ Longitudinal analysis $(n 99)^{*}$} \\
\hline & Mean & SD & Mean & SD \\
\hline Dietary Ca intake (mg/d) & 870 & 450 & 800 & 360 \\
\hline Age (years) & 57 & 10 & 57 & 10 \\
\hline Weight (kg) & 83 & 12 & 83 & 13 \\
\hline Height (cm) & 177 & 6 & 177 & 6 \\
\hline $\mathrm{BMI}\left(\mathrm{kg} / \mathrm{m}^{2}\right)$ & 26.5 & $3 \cdot 4$ & $26 \cdot 6$ & 3.6 \\
\hline Physical activity (MET h/d) & 32 & 5 & 33 & 6 \\
\hline Serum 25-hydroxyvitamin $\mathrm{D}(\mathrm{nmol} / \mathrm{l})$ & 92 & 33 & 95 & 34 \\
\hline Dietary vitamin $D$ intake $(\mu \mathrm{g} / \mathrm{d})$ & 2.9 & 3.8 & $3 \cdot 1$ & 4.8 \\
\hline \multicolumn{5}{|l|}{ History of fracture } \\
\hline$n$ & \multicolumn{2}{|c|}{169} & \multicolumn{2}{|c|}{57} \\
\hline$\%$ & \multicolumn{2}{|c|}{52} & \multicolumn{2}{|c|}{57} \\
\hline \multicolumn{5}{|l|}{ Current smoker } \\
\hline$n$ & \multicolumn{2}{|c|}{10} & \multicolumn{2}{|c|}{6} \\
\hline$\%$ & \multicolumn{2}{|c|}{3} & \multicolumn{2}{|c|}{6} \\
\hline \multicolumn{5}{|l|}{ Bone mineral density $\left(\mathrm{g} / \mathrm{cm}^{2}\right)$} \\
\hline Lumbar spine (L1-4) & $1 \cdot 250$ & $0 \cdot 161$ & $1 \cdot 241$ & 0.158 \\
\hline Total hip & 1.080 & 0.136 & 1.087 & 0.129 \\
\hline Total body & $1 \cdot 255$ & 0.093 & $1 \cdot 259$ & 0.094 \\
\hline \multicolumn{5}{|l|}{ Bone density $t$-score $†$} \\
\hline Lumbar spine & 0.3 & $1 \cdot 3$ & 0.1 & $1 \cdot 3$ \\
\hline Total hip & -0.1 & $1 \cdot 0$ & -0.0 & $0 \cdot 1$ \\
\hline Parathyroid hormone (pmol/l) $\ddagger$ & $4 \cdot 1$ & $1 \cdot 3$ & 3.7 & $1 \cdot 0$ \\
\hline \multicolumn{5}{|l|}{ Markers of bone turnover $\ddagger$} \\
\hline Total alkaline phosphatase (U/I) & 63 & 19 & 60 & 11 \\
\hline PINP $(\mu \mathrm{g} / \mathrm{l})$ & 39 & 15 & 36 & 9 \\
\hline CTX $(\mu \mathrm{g} / \mathrm{l})$ & 0.26 & $0 \cdot 10$ & 0.25 & 0.08 \\
\hline
\end{tabular}

MET, metabolic equivalent of task; PINP, procollagen type-1 N-terminal propeptide; CTX, C-telopeptide; NHANES, National Health and Nutrition Examination Survey.

* Only men in the placebo group of the trial were included in the longitudinal analysis.

† Bone density $t$-score refers to the number of SD above or below the young adult mean (USA (Combined NHANES/Lunar) and Femur Reference Population (v112))

$\ddagger$ Measured in a subset of 150 participants (fifty from the placebo group of the trial and fifty from each of the two Ca-supplemented groups). 

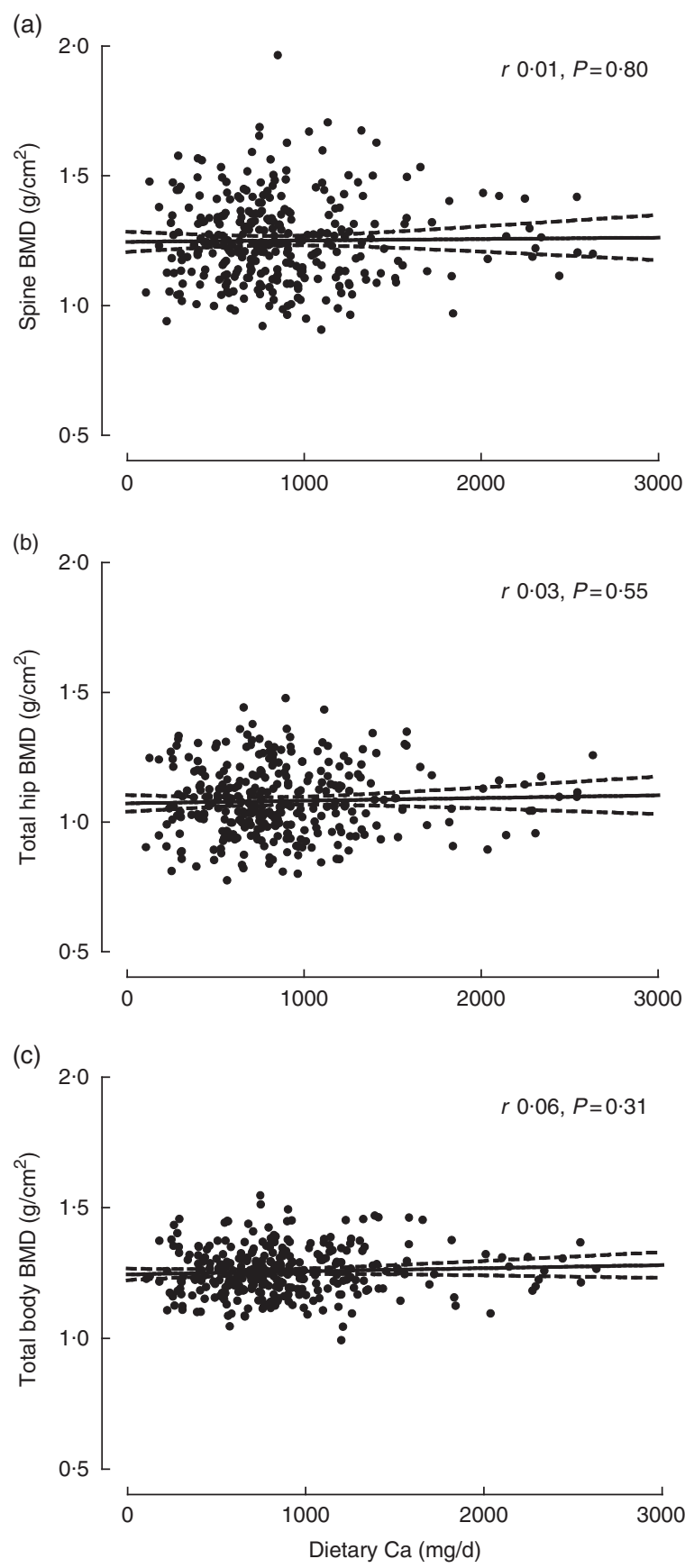

Fig. 1. Scatter plots of (a) lumbar spine bone mineral density (BMD) (b) total hip BMD and (c) total body BMD $v$. dietary calcium intake at baseline in older men. Values are line of best fit and $95 \% \mathrm{Cl}(n 323)$.

\section{Longitudinal analysis}

Over the 2-year study period (placebo group of the original trial only, $n$ 99), total body BMD did not significantly change from baseline $\left(-0.002 \mathrm{~g} / \mathrm{cm}^{2}, P=0.31\right)$ but total hip BMD decreased by $-0.004 \mathrm{~g} / \mathrm{cm}^{2}(P=0.02)$. Lumbar spine BMD increased over 2 years by $0.009 \mathrm{~g} / \mathrm{cm}^{2}(P=0.01)$. Dietary Ca intake was not correlated with the change in BMD at any site (Fig. 3). When we performed multiple regression analyses with change in BMD at each site as the dependent variable and dietary $\mathrm{Ca}$, age, weight,

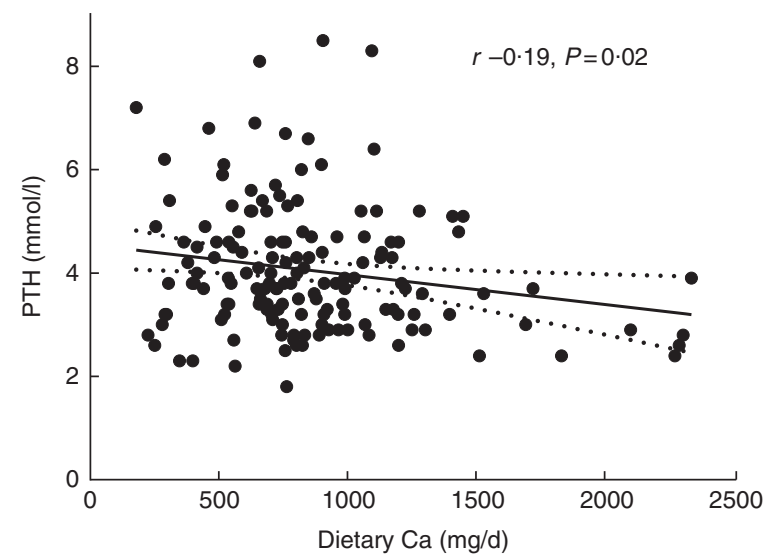

Fig. 2. Scatter plot of parathyroid hormone $(\mathrm{PTH}) \mathrm{v}$. dietary calcium intake at baseline in older men. Line of best fit and $95 \% \mathrm{Cl}$ are shown $(n 150)$.

Table 2. Predictors of parathyroid hormone (PTH) in men*

\begin{tabular}{lclc}
\hline & $\begin{array}{c}\text { Regression } \\
\text { coefficient }\end{array}$ & \multicolumn{1}{c}{$P$} & Partial $r^{2}$ \\
\hline Serum 25-hydroxyvitamin D (nmol/l) & -0.009 & 0.003 & 0.06 \\
Dietary Ca (400 mg/d)† & -0.159 & 0.03 & 0.03 \\
Weight $(\mathrm{kg})$ & 0.039 & 0.03 & 0.03 \\
Height $(\mathrm{cm})$ & -0.046 & 0.005 & 0.05 \\
Age (years) & 0.017 & 0.09 & 0.02 \\
\hline
\end{tabular}

* Model with PTH as the dependent variable, $P$ for model $<0.0001, r^{2}$ for model 0.18 ( $n$ 150).

$\dagger$ Regression coefficient shows the change in PTH per $400 \mathrm{mg} / \mathrm{d}$ increase in dietary Ca intake.

height, serum 25(OH)D, physical activity and smoking status as the independent variables, dietary $\mathrm{Ca}$ intake did not reach the required level of significance $(P<0 \cdot 15)$ for inclusion in the models for change in BMD at any site.

Dietary Ca intake was assessed again at the end of the 2-year study period (placebo group only, $n$ 99) and had increased by an average of $126 \mathrm{mg} / \mathrm{d}(P=0.003)$. We repeated the analyses described above using the average of baseline and 2-year dietary $\mathrm{Ca}$ intake as the independent variable, with no material change in the findings. We also repeated the analyses using only 2 -year dietary $\mathrm{Ca}$ intake as the independent variable, and again the findings were similar.

\section{Discussion}

We utilised data from a cohort of healthy men enrolled in a randomised controlled trial to examine the relationship between dietary $\mathrm{Ca}$ and bone health. Dietary Ca intake was not associated with BMD at baseline ( $n$ 323), nor with change in BMD over 2 years ( $n$ 99). Ca intake was inversely associated with PTH, but was not related to bone turnover assessed through the markers ALP, CTX and PINP ( $n$ 150). A body of research suggests dietary $\mathrm{Ca}$ intake does not influence bone loss in older women ${ }^{(11)}$. The present study extends these findings to men, and suggests that efforts to increase Ca intake are unlikely to have an impact on the prevalence of and morbidity from male osteoporosis. 

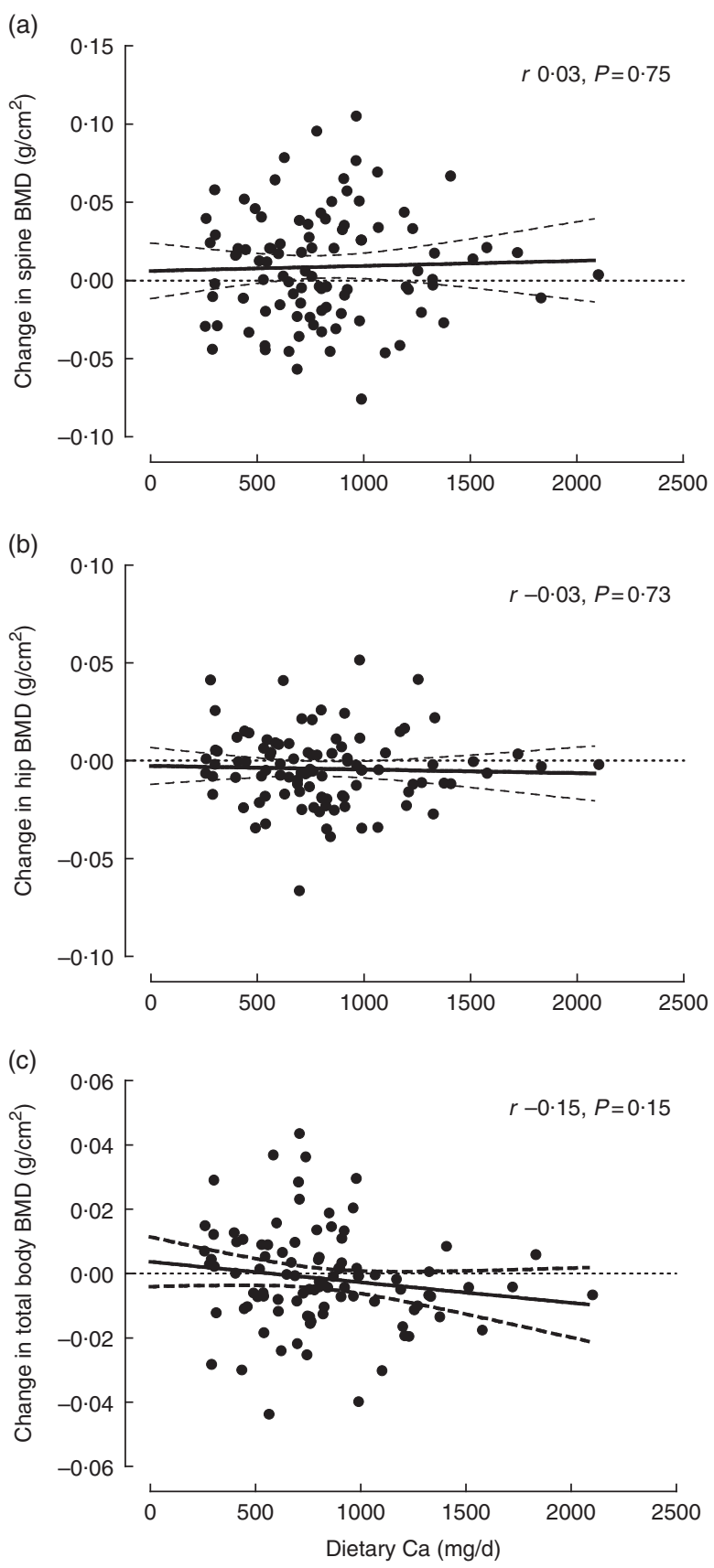

Fig. 3. Scatter plots of (a) change in lumbar spine bone mineral density (BMD) (b) change in total hip BMD and (c) change in total body BMD over 2 years $v$. dietary calcium intake at baseline in healthy older men. Line of best fit and $95 \% \mathrm{Cl}$ are shown $(n 99)$.

In men, there is evidence of a slow but continuous loss of bone from the time of early adulthood. Rates of bone loss of $-0 \cdot 1$ to $-0 \cdot 5 \% /$ year have been reported in men during middle to older age ${ }^{(5,24)}$, with the rate of loss tending to increase among elderly men ${ }^{(6,24)}$. These rates are broadly consistent with those observed in our study at the total hip $(-0 \cdot 2 \%$ /year $)$ and at the total body $(-0 \cdot 1 \% /$ year $)$. The increase we observed in lumbar spine BMD has been reported before ${ }^{(3)}$. This is likely an artifact of the projected area of the spine declining more rapidly than the mineral content, probably secondary to the decreasing height of intervertebral discs. The average age of men in the present cohort was 57 years, with the range of ages extending from 39 to 88 years. As fracture risk in men increases markedly at about 70 years ${ }^{(25)}$, the cohort of men studied represents one of key interest when considering interventions or lifestyle recommendations aimed at reducing future fracture risk. However, it is possible that because of the relatively low rate of bone loss among this age group, our study may have been underpowered to detect a very small effect of $\mathrm{Ca}$. Whether such a small relationship between $\mathrm{Ca}$ intake and bone loss would translate into a clinically important relationship between $\mathrm{Ca}$ intake and fracture risk is questionable.

Few previous studies have assessed the relationship between Ca intake and bone density in men. Three studies in older men have also reported no relationship between $\mathrm{Ca}$ intake and bone loss ${ }^{(14,16,17)}$, although one reported a trend for lower bone loss at the femoral neck with higher $\mathrm{Ca}$ intakes ${ }^{(15)}$. We also found no relationship between $\mathrm{Ca}$ intake and bone density in the crosssectional analysis at baseline. Other cross-sectional studies of men investigating $\mathrm{Ca}$ intake and current bone mass have reported no relationship between $\mathrm{Ca}$ intake and $\mathrm{BMD}^{(26,27)}$, an association only at very low intakes $(<400 \mathrm{mg} / \mathrm{d})^{(28)}$ or only very small differences in BMD $(<2 \%)$ across the normal dietary range of $\mathrm{Ca}^{(29)}$. An absent or a weak relationship between dietary $\mathrm{Ca}$ intake and bone density is supported by a recent meta-analysis of prospective cohort studies, which found no relationship between dietary $\mathrm{Ca}$ intake and fracture risk in men or women ${ }^{(30)}$. This is consistent with the finding from the development of fracture risk calculators that Ca intake does not have utility in fracture prediction ${ }^{(31,32)}$.

In the present analysis, dietary $\mathrm{Ca}$ intake was inversely related to PTH at baseline $(r-0 \cdot 19, n$ 323). We have previously reported an inverse correlation with $\mathrm{PTH}$ in a group of postmenopausal women using the same Ca questionnaire $(r-0 \cdot 26)^{(22)}$. Three additional studies in older adults have found inverse correlations between dietary Ca intake and PTH $(r-0 \cdot 08$ to $-0 \cdot 27)^{(33-35)}$, and a study including a younger population identified an inverse association only among those who were markedly vitamin D deficient ${ }^{(36)}$. This relationship presumably reflects an appropriate homoeostatic response of the parathyroids to $\mathrm{Ca}$ intake. An explanation for the absence of a relationship between dietary $\mathrm{Ca}$ and bone loss in observational studies has been that dietary Ca intake was not accurately measured. However, the biologically plausible relationship with PTH identified in the present study and others, indicates the tools used to assess dietary $\mathrm{Ca}$ intake are able to detect clinically meaningful differences in Ca intake.

As a low $\mathrm{Ca}$ intake is thought to promote bone loss by increasing the rate of bone turnover, we also examined associations between $\mathrm{Ca}$ intake and the markers of bone turnover ALP, CTX and PINP at baseline ( $n$ 150). No relationship between $\mathrm{Ca}$ intake and bone turnover was found. Ca intake was similarly not related to bone turnover in a cross-sectional analysis of men aged $20-87$ years ${ }^{(37)}$. The absence of a relationship between $\mathrm{Ca}$ intake and the bone turnover rate is consistent with the notion that $\mathrm{Ca}$ intake does not influence bone loss in men.

The inverse correlation between Ca intake and PTH, but lack of a relationship with bone loss and bone turnover, reflects the 
efficiency of the mechanisms involved in $\mathrm{Ca}$ homoeostasis. At low Ca intakes, higher PTH levels increase fractional Ca absorption in the gut (through hydroxylation of vitamin D) and its reabsorption in the renal tubule, whereas at higher $\mathrm{Ca}$ intakes both effects are reversed. The ability of humans to maintain Ca homoeostasis across a wide range of intakes, as suggested in the present study, is reflected in an analysis of Ca-balance data ${ }^{(38)}$. In this analysis, neutral Ca balance was achieved at an intake of $741 \mathrm{mg} / \mathrm{d}$, regardless of age or sex, but, importantly, Ca homoeostasis was found to be tightly controlled across the typical dietary range $(415-1740 \mathrm{mg} / \mathrm{d})$.

The absence of a relationship between dietary Ca intake and bone loss in observational studies appears to be contradicted by the small beneficial effects observed in clinical trials of $\mathrm{Ca}$ interventions. In these trials, Ca supplementation is consistently shown to reduce PTH and bone turnover ${ }^{(39)}$ and slow bone loss, resulting in a small gain in BMD (approximately $1 \%)^{(13)}$. However, these gains occur during the first year of treatment, with no cumulative benefit to bone density with a longer duration of supplementation ${ }^{(13)}$. Thus, the early effects of a large increase in $\mathrm{Ca}$ intake on bone loss are probably due to the reduction in bone turnover and the associated filling-in of the remodelling space, and do not persist once a steady-state in bone remodelling is restored. Collectively, evidence from intervention and observational studies suggests long-term $\mathrm{Ca}$ intake doesn't influence the rate of bone loss, but large increases in $\mathrm{Ca}$ intake induce a transient change.

The present analysis was based on a cohort of predominantly white, vitamin D-sufficient men, and the null relationship we observed between $\mathrm{Ca}$ intake and BMD may not apply to other ethnic groups or to vitamin D-deficient populations. The observational nature of the study means there is the risk of residual confounding. We did not have data on energy intake, which correlates with body size and Ca intake, and therefore we were unable to adjust for this variable. However, if confounding from energy intake was present, we would have expected to see less bone loss at higher $\mathrm{Ca}$ intakes as opposed to the null relationship observed. Although our sample size was relatively small, as little research on bone metabolism has been performed in men, the present analysis provides a valuable contribution to this area. In addition to its focus on men, a strength of this study was the inverse relationship we observed between $\mathrm{Ca}$ intake and PTH. Although the FFQ we used to assess dietary $\mathrm{Ca}$ intake had not been previously validated in men, the inverse correlation between $\mathrm{Ca}$ intake and PTH provided an internal validation of this instrument. Furthermore, the relationship between $\mathrm{Ca}$ intake and BMD was substantiated through examination of the relationship between $\mathrm{Ca}$ intake and bone turnover.

The present demonstration of an absence of an effect of dietary $\mathrm{Ca}$ intake on current bone mass or on bone loss in normal men, together with the absence of an effect of Ca intake on bone turnover, contributes to the body of evidence suggesting that $\mathrm{Ca}$ intake, within the range studied here, is not a critical factor in the maintenance of bone health in older adults. Many of the messages being promulgated at the present time are based on the findings of Ca-balance studies and the shortterm effects of high-dose Ca interventions, which do not reflect those of long-term dietary intake. Messages to increase dietary Ca could be directing at-risk individuals away from considering interventions and strategies proven to influence long-term fracture risk.

\section{Acknowledgements}

This study was supported by the Health Research Council of New Zealand. S. M. B. is supported by an Auckland Medical Research Foundation Edith C. Coan Research Fellowship and a Kelliher Charitable Trust Emerging Research Start-Up Award. The funders had no role in the design, analysis or writing of this article.

S. M. B. and I. R. R. formulated the research question and designed the study, A. M. H. carried out the study, G. D. G. analysed the data and S. M. B. and I. R. R. wrote the manuscript, which was critically revised by all authors.

None of the authors has any conflicts of interest to declare.

\section{References}

1. Kanis JA, Johnell O, Oden A, et al. (2004) Epidemiology of osteoporosis and fracture in men. Calcif Tissue Int $\mathbf{7 5}$, 90-99.

2. Seeman E (1995) The dilemma of osteoporosis in men. Am J Med 98, 76S-88S.

3. Looker AC, National Center for Health Statistics (US) \& National Health and Nutrition Examination Survey (US) (2012) Lumbar Spine and Proximal Femur Bone Mineral Density, Bone Mineral Content, and Bone Area, United States, 20052008: Data from the National Health and Nutrition Examnination Survey (NHANES), Vital and Health Statistics Series 11. Hyattsville, MD: US Department of Health and Human Services, Centers for Disease Control and Prevention, National Center for Health Statistics.

4. Riggs BL, Melton LJ, Robb RA, et al. (2008) A populationbased assessment of rates of bone loss at multiple skeletal sites: evidence for substantial trabecular bone loss in young adult women and men. J Bone Miner Res 23, 205-214.

5. Slemenda CW, Christian JC, Reed T, et al. (1992) Long-term bone loss in men: effects of genetic and environmental factors. Ann Intern Med 117, 286-291.

6. Jones G, Nguyen T, Sambrook P, et al. (1994) Progressive loss of bone in the femoral neck in elderly people: longitudinal findings from the Dubbo osteoporosis epidemiology study. BMJ 309, 691-695.

7. Cummings SR \& Melton LJ (2002) Epidemiology and outcomes of osteoporotic fractures. Lancet 359, 1761-1767.

8. Wang M, Bolland M \& Grey A (2016) Management recommendations for osteoporosis in clinical guidelines. Clin Endocrinol (Oxf) 84, 687-692.

9. Institute of Medicine (2011) Dietary Reference Intakes for Calcium and Vitamin D. Washington, DC: The National Academies Press.

10. Kanis JA \& Passmore R (1989) Calcium supplementation of the diet - II. BMJ 298, 205-208.

11. Reid IR, Bristow SM \& Bolland MJ (2015) Calcium supplements: benefits and risks. J Intern Med 278, 354-368.

12. Stone KL, Seeley DG, Lui LY, et al. (2003) BMD at multiple sites and risk of fracture of multiple types: long-term results from the Study of Osteoporotic Fractures. J Bone Miner Res 18, 1947-1954. 
13. Tai V, Leung W, Grey A, et al. (2015) Calcium intake and bone mineral density: systematic review and meta-analysis. BMJ 351, h4183.

14. Hannan MT, Felson DT, Dawson-Hughes B, et al. (2000) Risk factors for longitudinal bone loss in elderly men and women: the Framingham Osteoporosis Study. J Bone Miner Res 15, $710-720$

15. Burger H, de Laet CE, van Daele PL, et al. (1998) Risk factors for increased bone loss in an elderly population: the Rotterdam Study. Am J Epidemiol 147, 871-879.

16. Dennison E, Eastell R, Fall CH, et al. (1999) Determinants of bone loss in elderly men and women: a prospective population-based study. Osteoporos Int 10, 384-391.

17. Zhou W, Langsetmo L, Berger C, et al. (2013) Longitudinal changes in calcium and vitamin D intakes and relationship to bone mineral density in a prospective population-based study: the Canadian Multicentre Osteoporosis Study (CaMos). J Musculoskelet Neuronal Interact 13, 470-479.

18. Reid IR, Ames R, Mason B, et al. (2008) Randomized controlled trial of calcium supplementation in healthy, nonosteoporotic, older men. Arch Intern Med 168, 2276-2282.

19. Carter GD, Carter CR, Gunter E, et al. (2004) Measurement of Vitamin D metabolites: an international perspective on methodology and clinical interpretation. I Steroid Biochem Mol Biol 89-90, 467-471.

20. Bolland MJ, Grey AB, Ames RW, et al. (2006) Determinants of vitamin $\mathrm{D}$ status in older men living in a subtropical climate. Osteoporos Int 17, 1742-1748.

21. Angus RM, Sambrook PN, Pocock NA, et al. (1989) A simple method for assessing calcium intake in Caucasian women. J Am Diet Assoc 89, 209-214.

22. Bolland MJ, Grey AB, Ames RW, et al. (2006) Fat mass is an important predictor of parathyroid hormone levels in postmenopausal women. Bone 38, 317-321.

23. Wilson PW, Paffenbarger RS Jr., Morris JN, et al. (1986) Assessment methods for physical activity and physical fitness in population studies: report of a NHLBI workshop. Am Heart J 111, 1177-1192.

24. Bakhireva LN, Barrett-Connor E, Kritz-Silverstein D, et al. (2004) Modifiable predictors of bone loss in older men: a prospective study. Am J Prev Med 26, 436-442.

25. Jones G, Nguyen T, Sambrook PN, et al. (1994) Symptomatic fracture incidence in elderly men and women: the Dubbo Osteoporosis Epidemiology Study (DOES). Osteoporos Int $\mathbf{4}$, $277-282$.

26. Lau EM, Leung PC, Kwok T, et al. (2006) The determinants of bone mineral density in Chinese men - results from Mr. Os (Hong Kong), the first cohort study on osteoporosis in Asian men. Osteoporos Int 17, 297-303.
27. Bischoff-Ferrari HA, Kiel DP, Dawson-Hughes B, et al. (2009) Dietary calcium and serum 25-hydroxyvitamin D status in relation to BMD among US adults. J Bone Miner Res 24, 935-942.

28. Kim MK, Chon SJ, Noe EB, et al. (2017) Associations of dietary calcium intake with metabolic syndrome and bone mineral density among the Korean population: KNHANES 2008-2011. Osteoporos Int 28, 299-308.

29. Cauley JA, Fullman RL, Stone KL, et al. (2005) Factors associated with the lumbar spine and proximal femur bone mineral density in older men. Osteoporos Int $\mathbf{1 6}$, 1525-1537.

30. Bolland MJ, Leung W, Tai V, et al. (2015) Calcium intake and risk of fracture: systematic review. BMJ 351, h4580.

31. Kanis JA, Oden A, Johansson H, et al. (2009) FRAX and its applications to clinical practice. Bone 44, 734-743.

32. Nguyen ND, Frost SA, Center JR, et al. (2008) Development of prognostic nomograms for individualizing 5-year and 10-year fracture risks. Osteoporos Int 19, 1431-1444.

33. Kinyamu HK, Gallagher JC, Rafferty KA, et al. (1998) Dietary calcium and vitamin D intake in elderly women: effect on serum parathyroid hormone and vitamin D metabolites. $A m J$ Clin Nutr 67, 342-348.

34. Adami S, Viapiana O, Gatti D, et al. (2008) Relationship between serum parathyroid hormone, vitamin D sufficiency, age, and calcium intake. Bone 42, 267-270.

35. Joo NS, Dawson-Hughes B, Kim YS, et al. (2013) Impact of calcium and vitamin $\mathrm{D}$ insufficiencies on serum parathyroid hormone and bone mineral density: analysis of the fourth and fifth Korea National Health and Nutrition Examination Survey (KNHANES IV-3, 2009 and KNHANES V-1, 2010). J Bone Miner Res 28, 764-770.

36. Steingrimsdottir L, Gunnarsson O, Indridason OS, et al. (2005) Relationship between serum parathyroid hormone levels, vitamin D sufficiency, and calcium intake. JAMA $\mathbf{2 9 4}$ 2336-2341.

37. Chaitou A, Boutroy S, Vilayphiou N, et al. (2011) Association of bone microarchitecture with parathyroid hormone concentration and calcium intake in men: the STRAMBO study. Eur J Endocrinol 165, 151-159.

38. Hunt CD \& Johnson LK (2007) Calcium requirements: new estimations for men and women by cross-sectional statistical analyses of calcium balance data from metabolic studies. Am J Clin Nutr 86, 1054-1063.

39. Bristow SM, Gamble GD, Stewart A, et al. (2014) Acute and 3-month effects of microcrystalline hydroxyapatite, calcium citrate and calcium carbonate on serum calcium and markers of bone turnover: a randomised controlled trial in postmenopausal women. Br J Nutr 112, 1611-1620. 